\title{
Small interfering RNA (siRNA): a hope for the loss-of- function studies in anesthesiology?
}

\author{
Yun Hong Kim \\ Department of Anesthesiology and Pain Medicine, Kangbuk Samsung Hospital, Sungkyunkwan University School of Medicine, Seoul, Korea
}

Since the recombinant plasmid was first introduced into E.coli by Cohen et al. [1] in 1973, genetic engineering (modification) has been developing rapidly. Genetic modifications in vivo or in vitro, which have an effect on the expression of specific proteins, such as channel, receptor, enzyme, and signals, are actively applied in the researches that highlight the relationship between the effects of anesthetics and functions of specific proteins [25]. The loss-of-function studies that control the function of proteins, are very important in clarifying the mechanism of action of anesthetics. To achieve this, post-translational proteins are directly inhibited by pharmacological inhibitors [6,7], or are indirectly suppressed by transforming DNA construct via mutation or recombination, which is known as transgenic knockout technique [8]. After the creation of knockout mice by Capecchi et al. in 1989, transgenic knockout techniques are not only available in vitro, but are also available in vivo animal studies (In 2007, Capecchi MR won a nobel prize in appreciation for creating transgenic knockout mice). Although the gene knockout technique has several advantages over conventional laboratory techniques, including a long-lasting and a definitive specific gene-silencing effect, it is not easy to get a genetic engineering technique and initially it is expensive to purchase a gene knockout animal. After the discovery of RNA interference (RNAi) that is induced by short sequence-specific double stranded RNA (dsRNA) ranging in size from 20 to 25 nucleotides in length, and that targets the complementary sites on mRNA, exogenous synthetic small interfering RNA (siRNA) could be used to induce post-transcriptional gene silencing and that was first applied in mammalian cells in 2001 [9]. Because well-designed siRNA can induce suppression of any gene through forming the RNA- induced silencing complex (RISC) in the cytoplasm, the research for therapeutic application of siRNA against cancer, viral infection, and neurodegenerative disease are now being performed and clinical trials are also being carried out $[10,11]$. Moreover, if methods for effective in vivo delivery of siRNAs into the target tissue or organ are developed, anesthesiologists could easily achieve control over the tissue or organ-specific expression of individual target proteins used in the research. It is known that systemically or locally delivered siRNA induces a temporary gene expression knockdown effect by up to $90 \%$ from 48 hours to 3 weeks in animal experiments for eyes, brain, spinal cord, lungs, subcutaneous tissue, vagina, skin, isolated tumor, heart et al. [10-12]. But systemically or locally administered siRNA is easily degraded during the phase of delivery to the target cells by endogenous enzymes or phagocytosis, and its permeation through the negatively charged hydrophobic cellular membranes is difficult because of its high molecular weight $(\sim 13 \mathrm{kDa})$ and its too negatively charged character. Also, the cytoplasmic concentration of transfected siRNA is reduced as cell divisions progress and, cell types and pericellular factors influencing cell division may influence the gene silencing effects over time [13]. In general, the small size of the siRNA is considered not to provoke cytosolic dsRNA-mediated interferon response. But, it is reported that transfected siRNA is linked to the production of interferon and interleukin in some cell types (plasmacytoid dentritic cells, macrophages), that may be related to immunotoxicity. And, it is also known that a siRNA could degrade not only the targeted

Corresponding author: Yun Hong Kim, M.D., Department of Anesthesiology and Pain Medicine, Kangbuk Samsung Hospital, Sungkyunkwan University School of Medicine, 108, Pyeong-dong, Jongno-gu, Seoul 110-746, Korea. Tel: 82-2-2001-2322, Fax: 82-2-2001-2326, E-mail: yhkim12@yahoo.co.kr

(c) This is an open-access article distributed under the terms of the Creative Commons Attribution Non-Commercial License (http:// creativecommons.org/licenses/by-nc/3.0/), which permits unrestricted non-commercial use, distribution, and reproduction in any medium, provided the original work is properly cited. 
mRNAs but also the unintended mRNAs with sequence homology with the siRNA, which is called the "off-target effect". As a result, there is a chance of inaccurate results in the experiments undertaken using the suppression of a specific protein and even for assessing the cytotoxicity. To correct such shortcomings, it is recommended that the administered doses of siRNA should be reduced while constructing the design of experiments for successful delivery of siRNA into a target cell or tissue. And, the nucleotide modifications of siRNA can be applied in order to prevent the 'off-target effect' [13]. Ki et al. [14] in this month's journal found the lowest concentration of siRNA against a specific protein that could not only induce effective transfection of siRNA but also show maximum RNAi-mediated gene silencing while not demonstrating cytotoxicity, both in the cultured astrocytes and microglial cells [14]. Identifying the lowest effective concentration of siRNA is desirable for minimizing the adverse reactions and also for improving the cost-effectiveness for researchers who are always confronted with the problem of lack of financial support for experiments. Although Ki et al. [14] have clarified that each cell type has its own characteristic for determining the lowest concentration of siRNA against a specific protein at which the targeted mRNA is effectively silenced ( $5 \mathrm{nM}$ for astrocytes, $20 \mathrm{nM}$ for microglial cells), it was not determined whether that concentration of siRNA in each cell is related to the 'off-target effect' (knockdown of untargeted proteins). Tschuch et al. [15] reported that $5 \mathrm{nM}$ siRNA against green fluorescent protein (GFP), which was the protein used in the study by Ki et al. [14], can suppress the expression of the other unintended proteins (CYLD and SOAT) in HeLa and HEK cells. This fact implies that untargeted proteins may also be suppressed by $20 \mathrm{nM}$ siRNA against GFP, the lowest concentration suppressing the target gene expression both in the astrocytes and microglial cells in the study by Ki et al. [14], and thereby the accuracy of results of the study may be adversely affected. Thus before performing research using the procedure for siRNA silencing of expression of a specific protein, it is necessary not only to find out the lowest concentration at which a target protein could be controlled, but also to investigate the concentration of siRNA at which cellular apoptosis and expression of stress-response proteins are not triggered [16]. Ki et al. [14] tried to estimate the degree of cytotoxicity at the measured concentration of siRNA using the MTT assay, by which cell viability can be assessed. At present, control of protein expression by siRNA-induced transcriptional gene silencing is on the rise in the field of laboratory research. But, siRNA can provoke 'off-target effect' and immunomodulation, and the time course of siRNA-induced gene silencing is still unclear. So, results of the study may be adversely affected. Further research is needed to confirm the accuracy of results of the RNA interference experiments using siRNA.

\section{References}

1. Cohen SN, Chang AC, Boyer HW, Helling RB. Construction of biologically functional bacterial plasmids in vitro. Proc Natl Acad Sci U S A 1973; 70: 3240-4.

2. Takei T, Saegusa H, Zong S, Murakoshi T, Makita K, Tanabe T. Anesthetic sensitivities to propofol and halothane in mice lacking the R-type (Cav2.3) Ca2+ channel. Anesth Analg 2003; 97: 96-103.

3. Höcker J, Paris A, Scholz J, Tonner PH, Nielsen M, Bein B. Differential effects of alpha 2-adrenoceptors in the modulation of the thermoregulatory response in mice induced by meperidine. Anesthesiology 2008; 109: 95-100.

4. Célérier E, González JR, Maldonado R, Cabañero D, Puig MM. Opioid-induced hyperalgesia in a murine model of postoperative pain: role of nitric oxide generated from the inducible nitric oxide synthase. Anesthesiology 2006; 104: 546-55.

5. Fanelli V, Puntorieri V, Assenzio B, Martin EL, Elia V, Bosco M, et al. Pulmonary-derived phosphoinositide 3-kinase gamma (PI3K $\gamma$ ) contributes to ventilator-induced lung injury and edema. Intensive Care Med 2010; 36: 1935-45.

6. Wang L, Wu B, Sun Y, Xu T, Zhang X, Zhou M, et al. Translocation of protein kinase $\mathrm{C}$ isoforms is involved in propofol-induced endothelial nitric oxide synthase activation. Br J Anaesth 2010; 104: 606-12.

7. Ding Q, Wang Q, Deng J, Gu Q, Hu S, Li Y, et al. Sevoflurane preconditioning induces rapid ischemic tolerance against spinal cord ischemia/reperfusion through activation of extracellular signal-regulated kinase in rabbits. Anesth Analg 2009; 109: 1263-72.

8. Sato Y, Kobayashi E, Murayama T, Mishina M, Seo N. Effect of $\mathrm{N}$-methyl-D-aspartate receptor epsilon1 subunit gene disruption of the action of general anesthetic drugs in mice. Anesthesiology 2005; 102: 557-61.

9. Elbashir SM, Harborth J, Lendeckel W, Yalcin A, Weber K, Tuschl T. Duplexes of 21-nucleotide RNAs mediate RNA interference in cultured mammalian cells. Nature 2001; 411: 494-8.

10. Manjunath N, Dykxhoorn DM. Advances in synthetic siRNA delivery. Discov Med 2010; 9: 418-30.

11. Vidalin O, Muslmani M, Estienne C, Echchakir H, Abina AM. In vivo target validation using gene invalidation, RNA interference and protein functional knockout models: it is the time to combine. Curr Opin Pharmacol 2009; 9: 669-76.

12. Ye W, Ten X, He M, Yu Y, Huang H, Hu Y, et al. Suppression of heart NF-кB p65 expression by jugular vein injection of RNAi in mice. Methods Find Exp Clin Pharmacol 2010; 32: 391-400.

13. Whitehead KA, Langer R, Anderson DG. Knocking down barriers: advances in siRNA delivery. Nat Rev Drug Discov 2009; 8: 129-38.

14. Ki KH, Park DY, Lee SH, Kim NY, Choi BM, Noh GJ. The optimal concentration of siRNA for gene silencing in primary cultured astrocytes and microglial cells of rats. Korean J Anesthesiol 2010; 59: 403-10.

15. Tschuch C, Schulz A, Pscherer A, Werft W, Benner A, Hotz-Wagenblatt A, et al. Off-target effects of siRNA specific for GFP. BMC Mol Biol 2008; 9: 60.

16. Semizarov D, Frost L, Sarthy A, Kroeger P, Halbert DN, Fesik SW. Specificity of short interfering RNA determined through gene expression signatures. Proc Natl Acad Sci U S A 2003; 100: 6347-52. 